Article

\title{
Towards Enhanced Transparency in Non-Annex 1 Countries? Challenges and Options for Measurement and Reporting in Georgia
}

\author{
Sophie Louise Gladov ${ }^{1, * \mathbb{D}}$, Iben Nathan ${ }^{2} \mathbb{D}$ and Morten Pedersen ${ }^{1}$ \\ 1 NIRAS A/S, 3450 Allerød, Denmark; mop@niras.dk \\ 2 Department of Food and Resource Economics, University of Copenhagen, 1165 København, Denmark; \\ in@ifro.ku.dk \\ * Correspondence: sologladov28@gmail.com
}

Received: 26 September 2020; Accepted: 25 November 2020; Published: 29 November 2020

\begin{abstract}
This paper explores what the main challenges are for Georgia and other non-Annex 1 countries to meet the requirements under the Paris Agreement's Enhanced Transparency Framework, and discusses what the options are for overcoming these challenges. The paper draws on primary data from Georgia's energy sector and on case-based literature from various non-Annex 1 countries. The literature points to challenges such as insufficient budgets, low capacity, and inadequate institutional set-ups, and proposes increased financial and technical support and standardized guidelines for measurement and reporting as best options. Cases from South Caucasus and Georgia are rare. We therefore examine how Georgia's current system for Measurement and Reporting is organized, and what the main technical-administrative challenges are for the sector to meet the transparency requirements as seen from key stakeholders' and implementers' perspectives. In addition to challenges similar to those identified in the literature, we find that the most fundamental challenge is a lack of domestic political motivation and support. The perceived complexity of the transparency requirements is a major deterrent in combination with the limited capacity to deal with it. We therefore focus our discussion on options for how to foster domestic political support, and argue that emphasizing existing and new co-benefits, including increasingly linking Measurement and Reporting to the carbon market, could be a way forward. Given the urgency of reducing emissions, we find that efforts towards reducing the complexity of the requirements, activities and tools for Measurement and Reporting (M\&R) could help adapt the Enhanced Transparency Framework to the actual situation of non-Annex 1 countries and make Measurement and Reporting more worthwhile for these countries.
\end{abstract}

Keywords: climate change; mitigation actions; measurement; reporting; enhanced transparency framework; Paris Agreement; energy efficiency; Georgia

\section{Introduction}

On December 12 2015, the Parties of the United Nations Framework Convention on Climate Change (UNFCCC) agreed on a comprehensive global treaty: the Paris Agreement. The collective goal was to keep "global warming well below 2 degrees Celcius and to pursue efforts to limit warming even further to 1.5 degrees" [1]. The main framework for achieving this goal was the Nationally Determined Contributions (NDCs), which describe each country's pledges to reducing national Greenhouse Gas emissions and adapting to the impacts of climate change [2]. The United Nations Environment Programme concluded, however, that the commitments were insufficient and that dangerous temperature increases of 3.2 degrees Celsius are likely before the end of the century. 
Thus, there is an urgent need for all countries not only to fulfill their pledges, but also to raise their ambitions [3].

In order to track progress and enhance credibility, the Paris Agreement obliges all parties to communicate reliable, transparent, and comprehensive information on their progress towards achieving their individual pledges [1]. For this purpose, the Agreement's Article 13 provides for the Enhanced Transparency Framework. This Framework outlines the general requirements for what information the parties must collect and how to submit it, or in other words, for their measurement, reporting, and verification systems (MRV). In the context of the UNFCCC and in our terminology, measurement $(\mathrm{M})$ means collecting relevant data on the progress with and impacts of, mitigation actions. Reporting $(\mathrm{R})$ means presenting the measured information in a transparent and standardized manner. Verification $(\mathrm{V})$ is to assess the completeness, consistency, and reliability of the reported information through an independent process [3,4]. The Enhanced Transparency Framework builds on the existing Transparency Framework under the UNFCCC, which distinguishes obligations of Annex 1 and non-Annex 1 countries [5](Annex 1 countries are industrialized countries that were members of the Organization for Economic Co-operation and Development (OECD) in 1992 and countries with economies in transition. Non-Annex 1 countries are developing countries and emerging economies), and intends to enhance it by adding to the obligations for both sets of countries [1].

This, however, signifies a fundamental paradox. Despite decades of efforts, many non-Annex 1 countries have, to date, not submitted information and reports on a regular basis, and their measurement and reporting has often been incommensurate with the UNFCCC requirements [6-9]. Lütken et al. (2012) [10] have argued that collecting and reporting data in a "transparent, accurate, complete, comparable and consistent manner" has even constituted one of the main challenges for these countries to comply with the UNFCCC. Thus, the countries that already struggle to meet current basic reporting obligations will now have to meet additional requirements.

The parties to the Paris Agreement agree that ensuring transparency and conducting MRV in all countries is essential for the fulfilment of the Paris Agreement's goals [11]. Why, then, is it so difficult for non-Annex 1 countries to establish MRV systems that work, and what are the options for these countries to overcome existing challenges in order to meet the increased requirements implied by the Enhanced Transparency Framework? These two questions have prompted our paper, and we have addressed them, first, through a review of case-based literature from various countries and, second, by taking a closer look at Georgia's MRV system. We consider this system as our main case and MRV of energy efficiency activities in public buildings in Georgia as our "embedded" case [12]. We focus on technical-administrative challenges for MRV systems as seen from the perspective of key stakeholders and implementers. With this, the aim is to provide new knowledge on domestic lessons learnt from the implementation of MRV in non-Annex 1 countries, and to discuss what the options are for enhancing MRV-activities in a manner that makes them worthwhile and meets the Enhanced requirements. Since verification mainly belongs to the international level, we will be concerned only with Measurement and Reporting, hereafter M\&R.

Before introducing the results, we will first examine what the Enhanced Transparency Framework's general requirements are to non-Annex 1 countries (Section 1.1). This is followed by a review of the case-based literature on M\&R in non-Annex 1 countries (Section 1.2). In Section 2, we explain our study design, methods, and materials. In Section 3, the result section, we first examine Georgia's current system for MRV, second the respondents' perceptions of challenges and options. In Section 4, there is a synthesis of our results from Georgia and the literature review, and a presentation of our stepwise model for how to overcome existing technical-administrative challenges domestically. Finding that a lack of political motivation and support is the most fundamental of the identified challenges, we focus the discussion on what the options are for overcoming this challenge. 


\subsection{What Is the Enhanced Transparency Framework, and What Are the Related New Requirements for MER?}

The Paris Agreement Article 13, the Enhanced Transparency Framework, builds on and enhances the existing arrangements under the UNFCCC for creating transparency of action and transparency of support [11,13]. The objective is "to promote effective implementation" of the Agreement and "to build mutual trust and confidence" among the parties so that all contribute their share to the global efforts of reducing emissions [1,2]. The parties expect that this will add to the Agreement's credibility and lay the foundation for increased ambitions for reduced emissions [1,11].

In 2018 at the $24^{\text {th }}$ Conference of the Parties (COP-24), the Parties adopted the common Modalities, Procedures, and Guidelines document, in which they, in accordance with Article 13, further defined and operationalized the Enhanced Transparency Framework [14]. This document intentionally builds upon and supersedes the existing M\&R system established under COP-16 in Cancun and COP-17 in Durban [1,14]. This implies that the parties will follow the existing M\&R system during a transition period until 2024 [11]. During this period, Annex 1 countries will continue to report as under the existing system by submitting annual National Greenhouse Gas Inventories, Biennial Reports, and fourth-yearly National Communications. The inventories and reports "shall" (obligatory) include information on Greenhouse Gas emissions and sinks, steps planned and taken to implement the Convention, and support provided to non-Annex 1 countries. Likewise, there continue to be considerably fewer requirements for non-Annex 1 countries. Thus, they only "shall" (obligatory) submit Biennial Update Reports and National Communications every fourth year. Biennial Update Reports, on the other hand, "should" (as appropriate) include updated information on "national circumstances," relevant institutional arrangements, inventories of Greenhouse Gas emissions and sinks, information on mitigation action needs, and the relevant support they receive from other countries [15].

From 2024, under the new system, measurement and reporting will become more similar for Annex 1 and non-Annex 1 countries, cf. Table 1. Thus, all countries must as previously submit National Communications every fourth year. However, Biennial Transparency Reports will substitute Biennial Reports and Biennial Update Reports. Further, all countries must follow the Modalities, Procedures and Guidelines for measurement $[1,11,14]$. Thus, all countries "shall" (obligatory) submit inventories on their emissions and sinks; information on their mitigation actions; and other information that makes it possible to track the progress they have made towards implementing and achieving their emission pledges. Moreover, it is a new element that the reports (as appropriate) "should" contain information on the countries' adaptation activities and on their mitigation actions' effects, not only on emission reductions but also on derived benefits, which are subsequently referred to as "co-benefits" [4,14]. In order to track the progress in implementing and achieving the pledges made in the Nationally Determined Contributions, Article 4 of the Paris Agreement requests all individual parties to identify the indicators most relevant to them. This could be, for instance, net-emissions and removals or percentagewise reduction of Greenhouse Gas intensity. It is also up to the individual countries whether they use quantitative or qualitative measurement of, say, co-benefits [14].

Table 1. Changed reporting requirements under the Enhanced Transparency Framework. Inspired by [11].

\begin{tabular}{ccc}
\hline Reporting & Before 2024 & After 2024 \\
\hline Annual Inventories & Annex 1 countries & Annex 1 countries \\
\hline $\begin{array}{c}\text { Fourth yearly National } \\
\text { Communications }\end{array}$ & All countries & All countries \\
\hline Biennial Reports & Annex 1 countries & \\
\hline Biennial Update Reports & Non-Annex 1 countries & All countries \\
\hline Biennial Transparency Reports & & \\
\hline
\end{tabular}

Nevertheless, there are also some differences in requirements for both sets of countries. Thus, only Annex 1 countries are obliged to submit Greenhouse Gas inventories every year and to provide 
information on the support they provide for mitigation and adaptation under the Agreement's article 9,10 , and 11. Non-Annex 1 countries "should", and thus are not required to provide information on the support they need and receive under the same articles. Furthermore, there is a flexibility built into the Modalities, Procedures and Guidelines for countries that lack capacity and previous experience with transparency under the Convention. These countries determine what kind of flexibility they should apply, but if applied, they must explain how, why, and what the underlying capacity constraints are [11]. The Modalities, Procedures and Guidelines allow for the parties to follow the new rules earlier than 2024 if they want to in order to gain experience with preparing for reporting under the Enhanced Transparency Framework [1,11,16].

In conclusion, the Enhanced Transparency Framework implies more similar measuring and reporting obligations for Annex-1 and non-Annex-1 countries as compared to the existing system. As seen from the perspective of non-Annex 1 countries, the Framework, moreover, implies more obligations, less standardization, and increased complexity [14]. This raises the question about what the options are for making the Framework operational, given the challenges non-Annex 1 countries have encountered with the existing system.

\subsection{What Challenges for Measurement and Reporting of Mitigation Actions Have Non-Annex 1 Countries Encountered under the Existing System According to the Literature?}

In addition to emphasizing a lack of available funding [7,16-18], the literature points to at least three main types of interrelated challenges for $M \& R$ in non-Annex 1 countries. We refer to these as technical challenges, coordination challenges, and motivation challenges.

With regard to technical challenges, several scholars indicate a lack of available technical expertise and skills, and, in some cases, a lack of the necessary technical equipment in non-Annex 1 countries [7,17,19-21]. Rebolledo (2014) [17] and Neef et al. (2015) [21] argue that missing expertise constitutes a challenge not only for carrying out actual measurement and reporting activities, but also for setting up legislation and regulation for M\&R. They and Wenzel (2016) [20] argue, moreover, that non-Annex 1 countries tend to outsource the specific tasks of designing and implementing M\&R systems to donor-projects and changing external consultants. The result is a limited transfer of skills within the system, and a loss of institutional memory.

The literature, moreover, points to different types of coordination challenges within and across institutions. At the level of implementation, Rebolledo (2014) [17] observes that data collection often takes place in an informal, ad-hoc and non-coordinated manner. In a particular case in Mexico, for instance, he found that the M\&R system had relied on several independent, isolated, and non-verified information systems. The result of these measurement inconsistencies was uncertainty about data quality and therefore about the effects of mitigation action. Wenzel (2016) [20], moreover, points to a lack of vertical coordination. Thus, based on experiences from several non-Annex 1 countries, roles and responsibilities were not clearly defined and the institutional set-up for $M \& R$ was informal and ad-hoc. This sometimes resulted in data-collection overlaps, and sometimes in no data collection at all, undermining the M\&R system's efficiency (also see [22-24]). Boyd et al. (2014) [18] and Chandran et al. (2018) [25] reference the challenge constituted by a lack of coordination across different policy domains, i.e., horizontal coordination $[18,25]$. The authors found that the complex and varying scale of mitigation actions in South Africa called for coordination of a wide range of actors, activities, databases, data, and legal and regulatory frameworks in order to increase possibilities for data sharing, ensure flows of information, and avoid "information silos" [18].

With regard to motivation challenges, the literature identifies a lack of awareness about, understanding of, and motivation for M\&R among key actors. Thus, states are sometimes concerned about intellectual property rights and sovereignty and therefore may lack motivation for sharing data with the international community [25]. Correspondingly, private companies may have trade secrets or other confidentiality issues that may reduce their motivation for sharing data with others [18]. Wenzel (2016) [20] has observed that, in contexts where climate change is not a priority among the 
general public, politicians are often not motivated for developing coherent policies and institutional frameworks for M\&R. Furthermore, they may lack motivation for developing M\&R policies because they are not aware of possible co-benefits and perceive M\&R mainly as a burden. Finally, at the level of implementation, Boyd et al. (2014) [18] found that, in South Africa, some key actors were not aware about the UNFCCC context of the M\&R activities in which they were involved. Since they did not understand the purpose of M\&R, they did not feel motivated [18].

The literature reviewed in this section draws on case studies from a limited number of countries, including Brazil, Mexico, Chile, Columbia, and South Africa [17,26]. To the authors' knowledge, no scholars have so far conducted studies on the challenges Georgia has encountered in establishing a system for $M \& R$, and in addition cases from other countries in the South Caucasus are rare. For this reason, Georgia, and in particular its energy sector, present a novel case for studying M\&R.

\section{Materials and Methods}

\subsection{Case and Context: Georgia's Energy Efficiency Programs for Buildings}

As noted, the case focus is Georgia's energy sector, and in particular three schools involved in a program for improving energy efficiency in public buildings [12]. Energy efficiency in public buildings is relevant to our study, first and foremost, because the energy sector plays a central role in Georgia's strategy for reducing greenhouse gas emissions. As stated in Georgia's NDC from 2015 [27], the country's unconditional target is: by 2030 to reduce emissions by $15 \%$ below the Business as Usual Scenario with the base year 2013. The conditional target is to reduce up to $25 \%$ below Business as Usual with international support $[27,28]$. One of the main NDC strategies is to increase energy efficiency in buildings [27]. For the time being, buildings consume around one-third of the country's energy use and, according to data from 2014, the use of energy for buildings is accountable for almost one-fifth of Georgia's total greenhouse gas emissions. Buildings in Georgia consume around one-third of energy use and, according to data from 2014, the use of energy for buildings is accountable for almost one fifth of Georgia's total emissions [29].

Several international actors have committed to assisting Georgia in improving its energy efficiency through different projects in the building sector [30] (e.g., European Bank for Reconstruction and Development, German Development Bank “Kreditanstalt für Wiederaufbau”, European Union, Asian Development Bank, Eastern Europe Energy and Environment Partnership, Nordic Environment Finance Cooperation (NEFCO), Council of European Development Bank (CEB) SIDA (Swedish International Development Cooperation Agency) and DANIDA (Danish Agency for International Development Aid)). These interventions assist Georgia, for instance, in preparing relevant primary and secondary legislation, such as the Energy Efficiency Law, the Regulation on Minimum Energy Performance Requirements [29,31,32], and in implementing specific energy efficiency programs and projects in the building sector (In 2017, for example, GIZ provided support for Georgia to strengthen the country's domestic capacities for enhanced reporting under the UNFCCC through the Information Matters project, implemented by the Deutsche Gesellschaft für Internationale Zusammenarbeit (GIZ) $\mathrm{GmbH}$ on behalf of the German Federal Ministry for the Environment, Nature Conservation, Building and Nuclear Safety (BMUB)). Most of the programs are still in a pre-feasibility or feasibility stage, and many of them have not yet considered whether or how, to link-up with the Paris Agreement's Enhanced Transparency Framework. Hence, our study of challenges and options is timely in relation to these projects, which include NEFCO's Project for Energy Efficiency in Buildings in Georgia (henceforth referred to as the Georgian Energy Efficiency Project) that is implemented by NIRAS (NIRAS is an international, multidisciplinary engineering consultancy) and constitutes the framework for our empirical study.

The Georgian Energy Efficiency Project is particularly relevant for this study because it is currently one of the country's largest international projects being implemented in the building sector [33] (The Eastern Europe Energy Efficiency Partnership (EP5) has given a EUR 1.87 million grant, NEFCO a 
loan of EUR 2.8 million to Georgia, and the Danish government has financed the preparatory work). Moreover, the project focus on energy efficiency in buildings is in line with Georgia's NDC pledges and priorities and plans to engage with the carbon market under the Paris Agreement. At the time of writing, however, the Georgian Energy Efficiency Project has only just started. The plan is to first implement a pilot program for 25 selected public buildings, including schools, kindergartens, and municipality administration offices. Project activities include improvement of roofs, walls and pipes; installation of new ventilation systems, boilers, insulation of heating pipes, thermostatic valves, and other automation control systems, LED lights and solar Photovoltaics energy systems [29,32]. The expectation is that these measures will generate 1,300 tons of $\mathrm{CO}_{2}$ reductions annually; that annual cost-savings will amount to approximately EUR 200,000; and that up to 10,000 people, mainly children, teachers, and public employees, will benefit from the upgraded buildings and better conditions. The first phases of the energy renovations of the 25 public buildings will end in 2020 and 2021 [29,31].

Challenges and options for Georgia to meet the requirements of the Enhanced Transparency Framework in general as well as for the Georgian Energy Efficiency Project to link-up with the Paris Agreement in particular, requires insights into Georgia's M\&R system not only at the national level, but also at local and intermediate levels. Currently, there is no system in place at the local level in Georgia for M\&R of emissions. For this reason, we selected three public schools involved with the Georgian Energy Efficiency Project as our "embedded cases" [12]. The advantage was that the three selected schools already collect and report data to Regional Centers (Later referred to as Resource Centers) and thus have some experience with $M \& R$, although for other purposes [34].

In the following, we refer to the institutional set-up and procedures in place to provide Georgia's Transparency Reporting to the UNFCCC's Stock-Taking as the national M\&R system. In addition, we refer to the institutions and procedures established at sub-national levels for collecting and reporting data from local units, such as schools, to higher administrative levels, such as the Regional Centers and Ministries, as the local M\&R system.

\subsection{Methods}

This paper draws on primary as well as secondary data. As previously indicated, the secondary data is derived from a literature review of scholarly works on $M \& R$ in general and $M \& R$ of mitigation actions in a non-Annex 1 country context. Relevant reports, guides and toolkits for establishing M\&R-related activities have also been consulted. In particular, we consulted literature on challenges and options for M\&R in non-Annex 1 countries.

The primary data derives partly from international and domestic government documents, such as the Paris Agreement, the Modalities Procedures and Guidelines, the Georgian government's Biennial Update Report, and national legal frameworks from Georgia, partly from semi-structured key informant interviews, which the first author conducted in Georgia in September 2019. Key informants were selected from the Ministry of Environmental Protection and Agriculture (henceforward the Ministry of Environment), the Ministry of Education, Science, Culture and Sports (henceforward, the Ministry of Education), and from Georgia's National Statistics Office (GEOSTAT). These respondents were selected because they are responsible for $M \& R$ within their respective institutions in Georgia and therefore have first-hand knowledge on existing M\&R practices, challenges, and opportunities. The key informants also included a Georgian technical manager (henceforward the $M \& R$ expert), who has years-long experience with the development and review of Greenhouse Gas inventories and MRV in Non-Annex 1 countries including Georgia; the head of one of Georgia's 68 Resource Centers, and the leaders of the three selected schools. Two of the three schools are located within the jurisdiction of the selected Resource Center. Note that Georgia's Resource Centers work as contact points between schools and the Ministry of Education, and the Resource Centers are responsible for implementing national policies and collecting and reporting any required information from the schools to the Ministry.

The main purpose of the interviews was to collect data on how the national and local M\&R systems function in reality, and to increase the research team's understanding of the most relevant 
actors' views on challenges and options. The study's main methodological foundation, thus, is a qualitative content analysis of selected stakeholders' experiences with the M\&R of mitigation actions in Georgia, in combination with secondary data.

The interviews with the key respondents on the concrete M\&R set-up were used to triangulate data from the Georgian Government's Biennial Update Report, its National Communication, as well as literature focusing on the Georgian case (e.g., Mdivani and Hoppe, 2016 [19]). This data enabled the identification of the differences between Georgia's formal and actual M\&R set-up. For aspects concerning the informants' views, the purpose was to gain insights in their individual perceptions of challenges related to $M \& R$ and mitigation actions' effects.

NIRAS' national project manager facilitated the interviews. He arranged meetings and provided assistance and interpretation whenever necessary. This meant that we could identify and get access to the key stakeholders immediately. The interviewees, consciously or unconsciously, could have overstated some challenges and ways forward in a way they thought could most likely prompt assistance from Georgian Energy Efficiency Project and NIRAS. It is also possible that they may have understated politically sensitive issues. On the other hand, the informants were quite straightforward in their views on national and local procedures. We therefore find it reasonable to conclude that our study provides insights to some of the most important technical and administrative challenges of Georgia's M\&R system, if not necessarily all of the challenges.

\section{Results: Georgia's National and Local M\&R Systems}

\subsection{What Is the Formal Institutional Set-Up of Georgia's National MER System?}

In its Biennial Update Report, the Georgian government depicts the formal institutional set-up of the national M\&R system by referring to the diagram in Figure 1 [34]. As illustrated, the Ministry of Environment is the main responsible unit for communication with the UNFCCC Secretariat. This includes submission of the National Communications (In Figure 1: NC) and Biennial Update Reports (In Figure: BUR) to the UNFCCC. More specifically, it is the three staff members of the Ministry of Environment's Climate Change Division (in Figure 1: CCD) that coordinate all issues regarding domestic climate change policies and prepare the reports. For instance, they compile Georgia's Greenhouse Gas inventory and are responsible for coordination of M\&R activities. Since January 2020, they also work as the secretariat for the Climate Change Council (Note that it is an exception that Figure 1 uses the term Climate Change Commission. In general it is referred to as the Climate Change Council) ([34], which consists of ministers from a broad range of relevant ministries. Finally, this small division coordinates all climate related issues under the Paris Agreement and reviews the National M\&R system. Further, it may create and approve working groups including for $M \& R[28,34]$. 


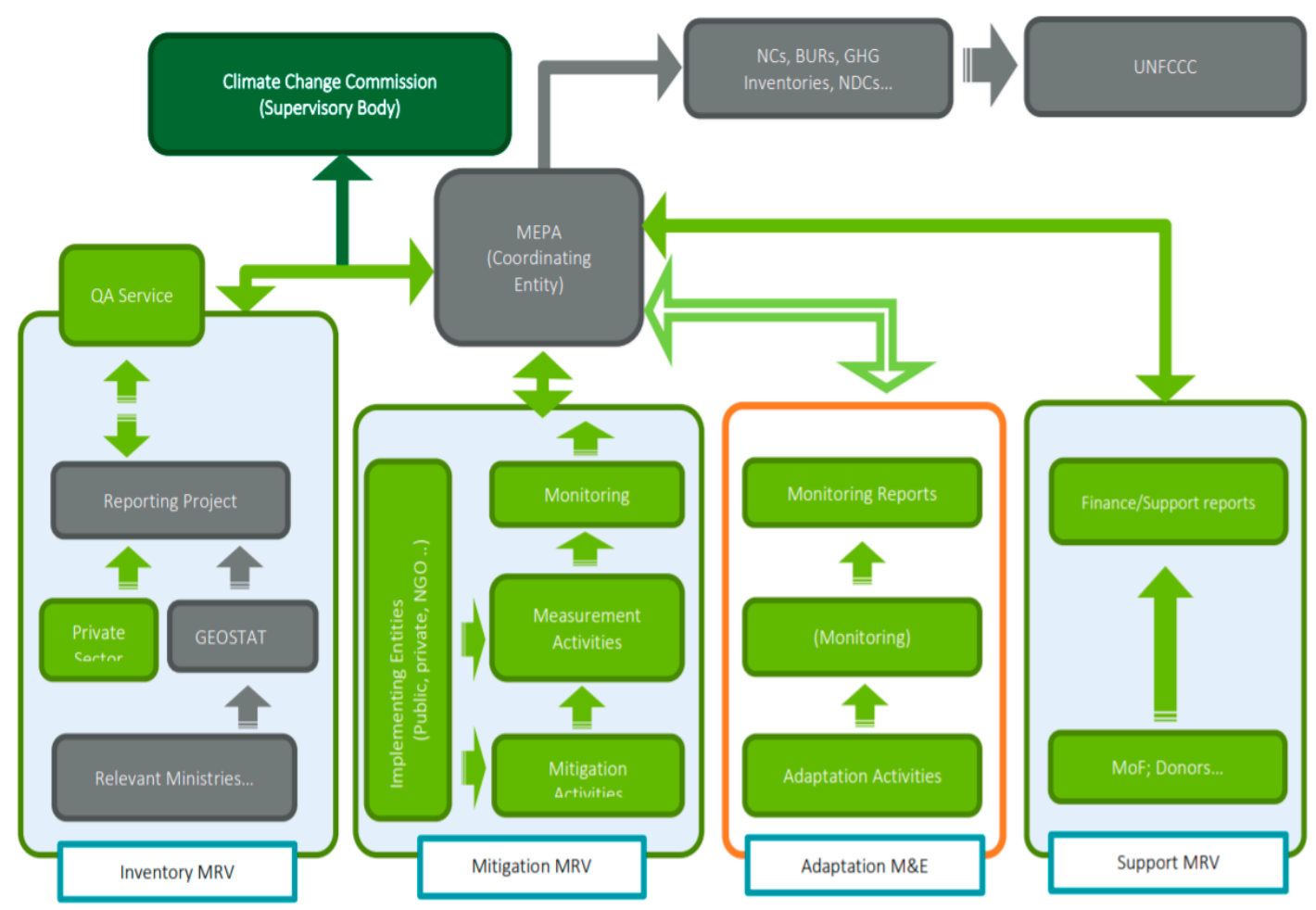

Figure 1. Formal Institutional Framework for Georgia's National Measurement and Reporting (M\&R) system (current and proposed combined. MEPA refers to the Ministry of Environmental Protection and Agriculture). Figure 1 [34]: Grey-colored boxes are elements that are currently in place. Light green boxes are elements deemed necessary for a holistic M\&R system. Dark green boxes are proposed additional elements that could strengthen the system further.

Figure 1 further illustrates that the National Communications and Biennial Update Reports rely on data collection and implementation through four sub-systems. These are (1) Inventory M\&R, (2) Mitigation $M \& R$, (3) Adaptation $M \& R$, and (4) Donor Support M\&R. Since the research is concerned with Georgia's M\&R system for mitigation activities, we will focus only on the two former systems.

Georgia's system for Inventory M\&R covers data on national emissions and relies on the relevant ministries reporting their data via GEOSTAT. The Ministry of Environment (2019) [34] characterizes Georgia's Inventory M\&R as the most advanced of the four sub-systems. Nevertheless, two elements of this sub-system are still not in place. These are the reporting of emissions from the private sector, and quality assurance of the reports. Based on this subsystem, the Ministry of Environment has up until now prepared and submitted three National Communications and is in the process of developing the fourth. Moreover, the Ministry of Environment has submitted two Biennial Update Reports [34], and the Environmental Information and Education Centre has prepared the Fifth National Inventory Report. This has occurred with the Global Environment Facility's financial assistance and through the support of independent international and local experts, as the work with the reports is too extensive for the Climate Change Division to manage on its own [28,34].

Georgia's M\&R sub-system for mitigation actions consists of four elements: mitigation activities, measurement activities, monitoring activities, and implementing entities. The Ministry of Environment (2019) [34] does not provide any details about the procedural set-up of these elements, and Figure 1 indicates that none are currently in place. Respondents from the Ministries confirmed this. In spite of this, the Biennial Update Reports contain some information on registered mitigation projects in Georgia, including the progress of their implementation, and estimated emission reduction outcomes. However, this information is not complete. Respondents from the Ministry of Environment clarified that Georgia's mitigation actions, for instance in Clean Development Mechanism (CDM) projects, have not yet been subject to systematic M\&R. 
With regard to the collection of data, the Ministry of Environment (2019) explained that there are no formal procedures in place for any of the two subsystems. If the Ministry needs data from, e.g., kindergartens, it sends a request to the municipalities, who approach the kindergartens, which then collect the content and report back. This process can be time consuming and the response time can vary significantly. Thus, it may take up to 1.5 months before data from kindergartens or schools are available for the Ministry. The Ministry of Education explained that if the Ministry of Finance needs any data on schools, it sends a request to the Ministry of Education which goes through the Resource Centers. These Centers will report back based on data collection by schools, "if possible". GEOSTAT is also not able to collect its own data, but it may request and compile data from other institutions.

\subsection{What Is the Formal Institutional Set-Up of Georgia's Local MER System?}

While there are no fixed procedures for collection of data for Biennial Update Reports, some local facilities have systems in place for reporting certain data that could be relevant. Thus, our respondents from the Ministry of Education, the Resource Centers, and the schools replied that 3-4 times per year public schools collect and share data (e.g., in an Excel sheet) that details energy consumption, such as electricity and heating, utility bills, and other information for example purchase of school equipment, infrastructure, etc. The schools submit these reports to the Ministry of Education via the Resource Centers.

The three school leaders further informed us that the schools receive utility bills monthly from the utility companies. These bills contain data on exactly how much gas, electricity, and heating the schools consume, as well as the related costs. We have summarized the reporting process for public schools in Figure 2.

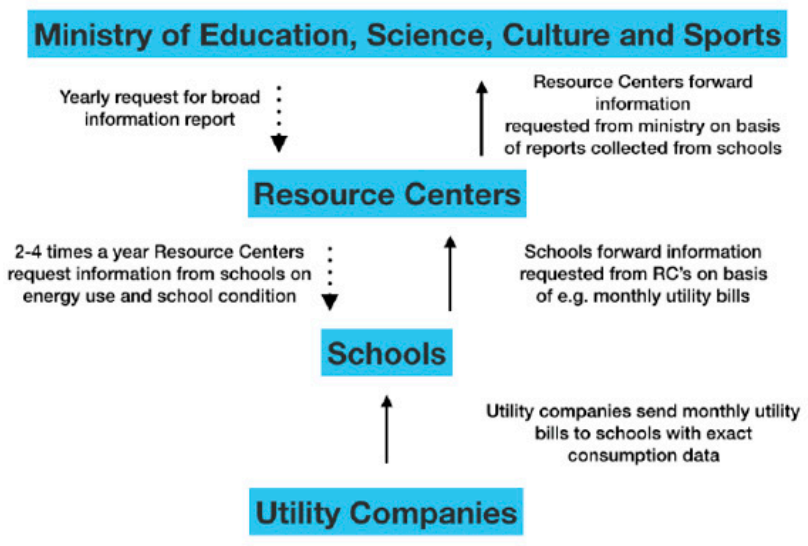

Figure 2. Flow of data on public schools' energy consumption.

Figure 2. Source: own elaboration based on interviews with Resource Center and school leaders. The flow of information begins with a request (dotted arrows) through Resource Centers and schools, who on the basis of their utility bills send requested information to Resource Centers who accumulate data from all schools and send the information to the Ministry of Education.

Even though the purpose of this local M\&R system is to account for the funding the schools receive from the Ministry of Education via the Resource Centers to cover utilities, infrastructure, and equipment, the reports contain some of the information needed for reporting to the UNFCCC. For instance, data on the schools' energy consumption are essential for measuring the emission effects of energy efficiency projects. In this sense, there is an option to integrate the existing local M\&R system with the new national system for reporting to UNFCCC.

In conclusion, the M\&R set-up in Georgia is still incomplete. On the one hand, there are some important elements in place, especially for the inventory, which has a longer history, since it was also part of the requirements of the existing Transparency Framework [13]. This system has produced some communications, information and plans for establishing a complete national M\&R set-up. On the other 
hand, there are still significant gaps. First, the Climate Change Division has very few employees relative to its portfolio of functions and responsibilities. Second, some of the planned elements of the inventory M\&R sub-system are still not in place. Third, the institutional framework for the mitigation action M\&R subsystem has not been formalized. Fourth, no established regular data collection procedures are in place outside the Ministry of Environment, and data collection is therefore mainly ad-hoc. In reality, the current formal M\&R system in Georgia does not meet the Enhanced Framework requirements. This raises the question of what the challenges are for Georgia to establish and implement a national M\&R system under the Enhanced Transparency Framework.

\subsection{What Are the Involved Actors' Perceptions of Georgia's Challenges with Regard to MER under the Existing and the Enhanced Transparency Transparency Framework?}

In order to discuss what the main challenges are for Georgia to meet the Enhanced Transparency requirements, it is necessary to make a distinction between national and local M\&R systems, and between data for inventory $M \& R$ and for $M \& R$ of mitigation actions. For the latter category, many of our respondents distinguished between measuring effects on emissions and the sustainable development effects. We will start out with the local perspective and ask what the main challenges are for the existing local system and for integrating the local system with the national system. Then, we will ask what the main challenges are to improve institutional set-up and M\&R procedures at the national level.

\subsubsection{Challenges for Local M\&R Systems in Georgia}

Based on insights from the three selected schools and Resource Centers, it would be obvious for the government, or for a project such as the Georgian Energy Efficiency Project, to integrate their local mitigation action M\&R with the system that is already in place. However, there are key challenges to overcome before such integration is possible. First, the reports from the three public schools do not contain all the data needed to track the performance of the mitigation action as required in the Modalities, Procedures and Guidelines, such as data on sustainable development effects and, depending on the chosen methodology, the data needed for measuring and reporting emissions. It will therefore be necessary to improve data availability and expand it.

Second, it is a challenge that there are currently no indicators or procedures for measuring mitigation activities and their development effects. For instance, the three school leaders interviewed all considered large temperature variations throughout the day and year as a major challenge for pupils and teachers. Possible development indicators for schools could therefore include, e.g., large variations in indoor climate conditions and temperature, which are potentially impacting pupils' health and learning abilities and the general quality of education. However, neither local utility bills nor other reports made by the schools contain this kind of information, and the school leaders informed us, that equipment, such as thermometers, is currently not available at their schools.

Third, it is likely that the schools will have to establish new M\&R procedures anyway. Moreover, the schools may have to obtain new competences and procure new equipment, such as thermometers, hydrometers and indoor $\mathrm{CO}_{2}$ meters (depending on methodologies chosen), and they may need to establish new measurement procedures. Our interviews indicated that although school leaders and Resource Centers are aware of many of the social and economic problems, such as the lack of energy supply and proper building conditions, they are not yet aware of the UNFCCC and Enhanced Transparency Framework requirements. Hence, awareness raising on M\&R, especially on the related benefits of the renovations, could be part of such a program.

Fourth, data collection and reporting currently occur ad hoc and only if the Resource Centers request it. There is also no formal or systematized communication of data from the public schools or the Regional Centers to the Ministry of Environment, which is responsible for the national M\&R system. Nor is there communication about such data from the Resource Centers or the Ministry of Economy and Sustainable Development, which is responsible for energy efficiencies. Therefore, there is a need for improved channels of communication between the different administrative levels. 
Finally, the M\&R expert respondent said that, according to her experience, data from schools and other public buildings in many other places are unavailable and of poor quality. She noted that she had experienced how some regions did not have inventories of the buildings they owned. Our results with regard to data availability therefore may give an overly positive picture of this local system as an option.

In conclusion, it could be an option to integrate the existing local systems for M\&R into an enhanced national M\&R system. For this to succeed, however, there are several challenges to overcome at both local and national levels. The following provides a closer look at what the challenges are for (improving) the National M\&R system, from the perspective of the key respondents.

\subsubsection{Challenges for (Improving) the National M\&R System in Georgia}

As previously indicated, a main challenge for the National M\&R system is that many of its planned elements are not yet in place, and that this is a problem in particular for mitigation action M\&R. Furthermore, it is not always possible for the Ministry of Environment to collect the necessary data, and when possible, measuring is ad hoc and reporting delayed. Respondents from the ministries pointed to three closely interrelated additional types of challenges for (improving) Georgia's National M\&R system: government and donors prioritize other activities because $M \& R$ is not domestically regulated;, new demands tend to be complex and there is limited national capacity to meet these demands; and politicians, government staff, and donors give insufficient attention to, and lack the motivation for, $M \& R$.

With regard to the lack of domestic regulation, the respondents from the ministries, as well as the M\&R expert explained that resources are scarce for which reason there is a need to prioritize between different activities. Since the collection of data is not compulsory outside the Ministry of Environment, they often prioritize other activities. The Ministry of Environment therefore suggested that a domestic legal framework for $M \& R$ would be "a necessary first step for the government" to meet its obligations under the Enhanced Framework. This would initiate M\&R activities and ease decision-making on M\&R at lower levels of the government system. Such a framework should include a demand for M\&R of mitigation actions as a mandatory element of any climate relevant project. The M\&R expert added that making $M \& R$ an indispensable government requirement would have the advantage of raising awareness about M\&R among other parties/stakeholders.

The respondents at the ministry level regarded M\&R of mitigation actions as a very complicated task. For instance, the Ministry of Environment respondent said:

"downscaling these requirements to project levels and being able to make these projects and measurements/reports feed into the international system will be very difficult [ ... ] because different mitigation actions require different solutions, and therefore there is no 'one fit solution' for monitoring mitigation projects which makes it very complicated".

Likewise, the M\&R expert pointed to the challenge of developing indicators and methods that can meet international requirements and simultaneously are relevant and adapted to local conditions. This includes measuring the sustainable development outcomes of different local facilities, such as public schools, nursing homes, and municipal offices, each with different purposes and development outcomes.

The respondents argued that there are not enough human resources in government to meet the reporting requirements. Thus, the Ministry of Environment emphasized that there are internationally trained and skilled people in place in the Ministry, who can compile and analyze data and report timely to UNFCCC. However, they get new tasks all the time, and the relevant office is understaffed. Furthermore, the government staff needs training in how to develop indicators and procedures for meeting the complicated transparency requirements (M\&R expert). The Ministry of Environment pointed to "bottle-necks in the system" that arise when local facilities such as public schools are requested to measure the impacts of emission reductions and sustainable development effects, because "they do not have the necessary skills and capacity." The GEOSTAT respondent argued that, in general, 
the Ministry of Environment has good ecologists but that they "lack expertise for handling the kind of statistics required both for inventory reports and mitigation actions." According to Mdivani and Hoppe (2016) [19], the paucity of experience and know-how at the government level in Georgia has been a challenge to climate change policies for years.

Most of the respondents explained that the government and donors have no focus on M\&R. The Ministry of Environment respondent mentioned the agricultural sector as an example:

"In the agricultural sector we have a relatively fixed number of cattle. To calculate emissions from cattle, we use default emissions, but this method cannot measure if we change the fodder and thereby cause less methane emissions. The main reason is the lack of focus on this kind of changes and that nobody require that we measure it. Therefore, we have a general overall picture of Georgia's emissions but very limited insights in the details".

The M\&R expert added that donor-funded energy efficiency projects do not integrate concerns about M\&R in their portfolios either. The Georgian Energy Efficiency Project's Feasibility Study and Energy Assessments of the three schools is a good example of this, since it has limited attention to M\&R. The likely reason is that this project, much like many other government and donor-supported energy efficiency programs, has other priorities in addition to reducing emissions, and that the stakeholders are not used to considering mainstreaming M\&R of mitigation actions and effects.

The respondents explained that this is mainly due to a lack of motivation among the key stakeholders. Thus, the M\&R expert explained that government "is currently resistant to take responsibility on the issue. It considers $M \& R$ as a cost heavy activity that limits development." Further, he stated that if government perceives M\&R in this way, then "no one will [feel motivated to] do M\&R." Along similar lines, the Ministry of Environment talked about M\&R of sustainable development effects as a "headache" due to its complicated nature ("M\&R of mitigation actions [ ... ] will be high priority when we have to start tracking NDC-implementation. However since this is not until 2021, we will postpone the headache" (Ministry of Environment 2019)).

The respondents from the Ministries and the expert were aware of some of the benefits coming more or less directly from $M \& R$. Thus, the $M \& R$ respondent considered $M \& R$ a useful tool for the government to learn whether the domestic actions they take are efficient. To this, the Ministry of Environment added:

"We know that it is necessary to get this system running and we want to track several cobenefits of these projects. We would be able to tell if, for example, health, air quality and other aspects related to the Sustainable Development Goals are improved. But also for the quality of inventories and in cases where our own ministries ask for indicator benefits"

Nevertheless, the Ministry of Environment found that the main incentive for Georgia's M\&R was that "we want to participate in the international climate policies and we can use it to attract technologies and funding to Georgia". If so, there is a "chicken-and -egg" situation, where politicians and government staff see the theoretical benefits of M\&R but do not prioritize it because they consider it a burden in terms of work and funding. For the same reason, they have not yet conducted any analysis of how $M \& R$ can contribute to highlighting the co-benefits that are specific to Georgia (M\&R expert, 2019, and Ministry of Environment, 2019). Again, this points towards a need for stronger political motivation and support for $M \& R$.

In conclusion, the lack of domestically regulated M\&R means that the government staff and donors do not conduct M\&R as it is not mandated nationally. Therefore, they prioritize other issues. Additionally, downscaling the Enhanced Transparency requirements to mitigation project level is difficult, especially taking into account that Georgia is still a relatively young democracy that is in the process of building solid, efficient institutions [19]. Combined with limited national capacity, M\&R becomes a burden rather than a benefit because neither donors nor government require $M \& R$ and there are no budgets for it. This results in a lack of focus on and motivation for conducting M\&R among government staff, politicians, and donors. 


\section{Discussion and Conclusions: What Are the Options for Enhancing Georgia's M\&R System?}

$M \& R$ of mitigation actions has been a requirement under the UNFCCC for more than 20 years. Yet, non-Annex 1 countries still struggle with the task. The literature we reviewed explained the difficulties mainly by a deficit of financial, technical, and/or inter-institutional (coordination) capacities at all administrative levels, ranging from national to local, between policy domains, and across the different phases of establishing and conducting M\&R. Some scholars, moreover, pointed to motivational challenges.

Our study pointed to similar types of challenges. However, one challenge that emerged more clearly in our case was the lack of motivation and support for $M \& R$ and the wide-ranging implications this had on all succeeding M\&R-related activities. The Georgian government staff who were interviewed considered M\&R necessary mainly because they perceived it as a requirement from the international community, but they also viewed it as a burden. There was, in other words, a drive for complying with international requirements, but not for developing local technical capacities, conducive institutions, such as enacting and enforcing national legislative frameworks or coordinating bodies, or guidelines and standards for M\&R [35,36].

So, what are the options for mitigating these challenges? One of the most common proposals in the literature for how to overcome the challenges is increased allocation of funds from Annex 1 to non-Annex 1 countries, and increased allocation of funds by national governments for M\&R purposes. In addition to this, several scholars point to the need for better domestic policies, and legislation as essential for overcoming these challenges $[17,18,23,24,37]$. Such frameworks should encompass all relevant aspects of a well-functioning M\&R system, including political support, conducive institutional arrangements, increased technical capacities, clear allocation of roles and responsibilities, and procedures for coordination of data collection and data sharing [23,38].

Based on our findings from Georgia and in the literature, we argue that there are at least four main options that can be taken on the national level for enhancing domestic M\&R systems, i.e., through (1) political motivation and support; (2) funding and technical capacity; (3) a conducive institutional set-up; and (4) domestic guidelines and standards for $M \& R$. These four elements are summarized in Figure 3, and as it further illustrates, we see these four main options as closely interrelated.

\section{Political motivation \& support}

\section{Funding and technical capacity}

\section{A conducive institutional set-up}

\section{M\&R guidelines and standards}

Figure 3. Options for enhancing domestic M\&R systems. 
As Figure 3 also illustrates, we find that political motivation and support is the most basic domestic element and option for improving $M \& R$, because it is a precondition for the success of any other element, as seen in the case of Georgia. Along similar lines, Figure 3, further, illustrates that a certain amount of funding and technical capacity must be available domestically, in order to set-up conducive institutions for M\&R, which again to a certain extent must be in place before it makes sense to develop well-adapted domestic M\&R guidelines and standards. Additional funding is thus an enabling factor for several factors, spanning from establishing proper measurement procedures (School leaders, 2019; Resource Center, 2019), to funding of M\&R activities (Ministry of Environment 2019), and further to increasing technical capacity to meet the complex requirements (Ministry of Environment, 2019; GEOSTAT, 2019). Yet, as our results have shown, funding and technical capacity is, to a large degree, dependent on a stronger political motivation and support. Another important option for enhancing domestic M\&R systems is through establishing a conducive institutional set-up and, lastly, to develop domestic guidelines and standards for M\&R are important.

Figure 3 summarizes the main options at the domestic level for improving $M \& R$, and it also works as a framework for what a sustainable M\&R system comprises. Yet, the four elements in the model are not "watertight". For example, once domestic guidelines and standards are in place, it may be clearer exactly what technical capacities and equipment is needed for conducting $M \& R$, what tasks and responsibilities should be allocated how, and whether there, therefore, is a need for further changes in the institutional set-up. It is also necessary for scholars or M\&R practitioners to, e.g., look deeper into the needed levels of funding, which types of funding are more efficient, what the proper timing and delivery is in different contexts, etc. Moreover, a broader focus on, for example, more cultural, social or political challenges could have contributed with other perspectives. Additionally, Figure 3 comprises the main domestic options for enhancing $M \& R$ systems. Yet, it is also essential to consider which options there are at the international level for enhancing $M \& R$ domestically. These and several other aspects, need to be investigated further, by, e.g., academia, businesses and M\&R actors, in order to contribute to an elaboration of the more distinct correlations, deeper perspectives and the broader context of the four elements in the M\&R figure.

Since domestic political motivation and support constitute the most basic element in our model for a sustainable M\&R system, we will mainly focus the rest of our discussion on which options the parties to the Paris Agreement have for fostering continued political motivation and support for sustainable M\&R systems in Georgia and other non-Annex 1 countries.

\subsection{How to Create Political Motivation and Support for MER Systems in Non-Annex 1 Countries?}

Some of the means highlighted in literature, i.e., by UNFCCC (2013) [24] and Marr et al. (2018) [37], to ensure support and increase motivation for $M \& R$ at various levels was for decision makers to engage a broad range of stakeholders both in the phase of designing domestic M\&R systems and during implementation. Yet, based on examples from international politics and regime studies, some argue that deep compliance with international agreements is less problematic, when states perceive of compliance as both in their direct interest and within their ability [36,39]. This implies that the effectiveness of a regime, among other things, depends on the measures it applies to make states comply, such as sanctions, incentives, transparency-enhancing practices, and a proper design of the scope and fit of regime obligations, and that there is a fit between requirements and parties' capacities to fulfill them [36,39]. The Paris Agreement accommodates some of these measures, for instance, through its Capacity Building Initiative for Transparency (incentive), the Enhanced Transparency Framework (transparency-enhancing practices) and flexibility for non-Annex 1 countries (proper design of scope and fit). Yet, as our study indicates, there is still a gap between the Enhanced Transparency Framework requirements and non-Annex 1 countries' capacity to achieve them. In the following, we will first discuss what measures could be applied to increase Georgia's direct interest to comply with the Enhanced Transparency Framework. Subsequently, we will discuss different perspectives on how to close the gap between requirements and capacity. 
Creating Motivation and Support through Increased Focus on Direct Interests

First, focusing more on national benefits of conducting $M \& R$ could contribute to creating motivation and support for sustained M\&R efforts in the country. Thus, a well-functioning $M \& R$ system already comes with several financial and other co-benefits; however, decision makers are not always fully aware of them, as was evident from our interviews with the government officials. For instance, conducting M\&R could contribute to highlighting and documenting national contributions to climate change and climate change mitigation and at the same time strengthen the position of non-Annex 1 countries in negotiations versus developed countries. Second, accentuating national mitigation efforts could concretely help attract financial, technological and capacity-building support. Third, M\&R is an opportunity to improve management of planning and implementation on different levels of governments, organizations and corporates and to prioritize mitigation efforts and make sure that efforts are deployed to where the potential impacts are highest [38]. Being able to report results and beneficiaries of the efforts made regarding NDC's could also engender broader public support for the climate agenda and strengthen the sustainability of the system [38]. Thus, framing M\&R as a national tool more than as a mean for transparency would likely contribute to increasing political will for M\&R.

Another important way that we see political will for M\&R could be increased is through a more active engagement between countries and/or businesses in Article 6 of the Paris Agreement on carbon markets, as this is an opportunity for non-Annex 1 countries to enable financial means directly benefitting the country [40]. For example, Georgia is currently pursuing a collaboration with the Swiss off-setting foundation KliK [41] on behalf of the Georgian government. It is the ambition that KliK will buy Georgian reductions, and in order to enure these reductions, it is also proposed that detailed $M \& R$ is set up for energy efficiencies in buildings. In this case, Georgia would both get increased support implementing an $M \& R$ system that is essential for documenting the $\mathrm{CO}_{2}$ credits that are intended to be sold to KliK, there would be local co-benefits from the projects in terms of improved conditions at -in this instance public schools-and incomes from selling credits can be lead directly back to, e.g., "climate investments" in the country. Another more indirect benefit from Article 6 is that international engagements such as selling $\mathrm{CO}_{2}$ credits, which will require $M \& R$, constitutes the most realistic opportunity for involving the high political level which will contribute to the most sustainable M\&R system. 4.1.2. Creating Motivation and Support through Increased Capacity to Deal with M\&R

According to some regime theories [36,39], creating compliance requires that countries consider it within their ability to meet the requirements of a regime. Accordingly, the reviewed literature tends to point to capacity development in non-Annex 1 countries as one of the main options for enhancing M\&R. Our study confirms that the complexity of the Enhanced Transparency Framework, despite the built-in flexibility mechanism, is a demotivating factor for Georgia's engagement in M\&R, but also that there are many technical-administrative challenges for developing the country's domestic M\&R capacity. Thus, donor projects, due to their short time-lines, tend to become "stop-and-go." For example, the prospects of getting support through the Capacity Building Initiative for Transparency specifically meant that Georgia would not engage any additional, unnecessary efforts until this point (Ministry of Environment, 2019). Scholars have suggested that governments and international donors could engage in capacity-building activities that are more long term and continuous, and that experts engage in transferring knowledge to domestic actors instead of just carrying out the tasks themselves [18,20,37]. One option could be to initiate long-term collaborations such as projects under Article 6 (such as KLiK). On the other hand, there is a serious downside of following such a long-term strategy. As Zahar (2019) [9] argues, due to the complex requirements and the challenges non-Annex 1 countries face, developing proper national M\&R systems may take decades. This is a long time in the perspective of the urgency of mitigating climate change.

Considering that the complexity of the Framework continues to be a barrier for non-Annex 1 countries, a second and more timely option for closing the capacity gap is to reduce the complexity of the Enhanced Transparency Framework itself. This could happen in several ways. A first simple step 
could be to align the way M\&R professionals speak of Enhanced Transparency Framework and M\&R. Currently, the terminology is quite complex, and, as highlighted by, among others, Boyd et al. (2014) [18], defining what $M \& R$ precisely entails is challenging. Likewise, we found that many stakeholders in Georgia are not familiar with the concepts. Second, when donors work with national governments and, in particular, local M\&R implementers, it could be advantageous to separate the task of conducting M\&R from the global transparency agenda and instead focus on national co-benefits to increase understanding and motivation for the task among local staff. Given the urgency for climate action, we find that a third option could be to adapt the current Enhanced Transparency Framework requirements and flexibility mechanism to the actual situation of the non-Annex 1 countries. It could, thus, be a viable solution to simplify requirements to scope, frequency and detail levels of reporting, simplifying institutional and procedural M\&R set-ups and guidelines as much as possible to decrease costs and increase motivation for $M \& R$, without the risk of being at the expense of raising ambitions.

In conclusion, enhancing transparency will very likely continue to constitute a significant challenge for non-Annex 1 countries. As far as we see it, the best option for overcoming the technical-administrative challenges is to focus on activities to boost political motivation and support whether this means linking up to the carbon market or emphasizing other co-benefits. Further, an option for overcoming the domestic challenges of political motivation and support could be through simplifying the requirements, activities, terminology and tools for $M \& R$, in order to make actions on M\&R more worthwhile for non-Annex 1 countries.

Author Contributions: Conceptualization, S.L.G., I.N. and M.P.; methodology, S.L.G. and I.N. validation, S.L.G., M.P.; writing—original draft preparation, S.L.G., writing—review and editing I.N. and S.L.G.; Visualization, S.L.G.; supervision; I.N. and M.P. All authors have read and agreed to the published version of the manuscript.

Funding: The APC was funded by NIRAS A/S.

Acknowledgments: We are very grateful to the interviewees and the insightful feedback provided to a draft version of this paper from Niels Bahnsen (NIRAS), Kakhaberi Mdivani (Formerly Ministry of Environment), Maia Tskhvaradze (Ministry of Environment) and Thomas Thorsch Krader (NIRAS). A further thanks to the two anonymous reviewers for their helpful comments.

Conflicts of Interest: The authors declare no conflict of interest.

\section{References}

1. UNFCCC. Paris Agreement. Available online: https://unfccc.int/sites/default/files/english_paris_agreement. pdf (accessed on 21 September 2020).

2. UNFCCC. Nationally Determined Contributions. Available online: https://unfccc.int/process-andmeetings/the-paris-agreement/the-paris-agreement/nationally-determined-contributions-ndcs (accessed on 21 September 2020).

3. UNEP. Emissions Gap Report 2019; UNEP: Nairobi, Kenya, 2019. [CrossRef]

4. Singh, N.; Finnegan, J.; Levin, K. MRV 101: Understanding Measurement, Reporting, and Verification of Climate Change Mitigation; World Resources Institute: Washington, DC, USA, 2016.

5. UNFCCC. Parties and Observers. Available online: https://unfccc.int/parties-observers (accessed on 9 December 2019).

6. UNFCCC. Handbook on Measurement, Reporting and Verification. For Developing Country Parties; United Nations Climate Change Secretariat: Bonn, Germany, 2014.

7. Klein, D.; Carazo, M.P.; Doelle, M.; Bulmer, J.; Higham, A. The Paris Agreement on Climate Change. Analysis and Commentary, 1st ed.; Oxford University Press: Oxford, UK, 2017; ISBN 978-878-933-8.

8. Dagnet, Y.; Waskow, D.; Elliott, C.; Northrop, E.; Thwaites, J.O.E.; Mogelgaard, K.; Krnjaic, M.; Levin, K.; Mcgray, H. Working Paper Staying on Track From Paris: Advancing the Key Elements of the Paris Agreement; World Resources Institute: Washington, DC, USA, 2016.

9. Zahar, A. The Paris Agreement's Implications for Monitoring, Reporting, and Verification of Greenhouse Gas Emissions and Climate-Related Policies and Measures in Developing Countries. SSRN Electron. J. 2019. [CrossRef] 
10. Lütken, S.; Aalders, E.; Pretlove, B.; Peters, N.; Olsen, K.H. Measuring, Reporting, Verifying. A Primer on MRV for Nationally Appropriate Mitigation Actions. 2012. Available online: https:/www.namapipeline.org/ Publications/MRV_PrimerNationallyAppropriateMitigationActions.pdf (accessed on 29 November 2020).

11. Dal Maso, M.; Canu, F.A. Unfolding the Reporting Requirements for Developing Countries under the Paris Agreement's Enhanced Transparency Framework; DTU: Copenhagen, Denmark, 2019.

12. Yin, R.K. Case Study Research: Design and Methods, 5th ed.; Sage: Thousand Oaks, CA, USA, 2014; ISBN 9781452242569.

13. UNFCCC. United Nations Framework Convention on Climate Change. Available online: https://unfccc.int/ resource/docs/convkp/conveng.pdf (accessed on 21 September 2020).

14. UNFCCC. Report of the Conference of the Parties Serving as the Meeting of the Parties to the Paris Agreement on the Third Part of Its First Session, Held in Katowice from 2 to 15 December 2018. Decision 18/CMA.1 (MPG'S). Available online: https:/unfccc.int/sites/default/files/resource/cma2018_3_add1_advance. pdf (accessed on 15 September 2020).

15. UNFCCC. Report of the Conference of the Parties on Its Seventeenth Session, Held in Durban from 28 November to 11 December 2011. Available online: https:/unfccc.int/resource/docs/2011/cop17/eng/09a01. pdf (accessed on 9 September 2020).

16. Winkler, H.; Mantlana, B.; Letete, T. Transparency of action and support in the Paris Agreement. Clim. Policy 2017, 17, 853-872. [CrossRef]

17. Rebolledo, E. Mexico. Building a Comprehensive National MRV Framework. Available online: https://www. transparency-partnership.net/sites/default/files/mexico_gpa_long_1.pdf (accessed on 23 September 2020).

18. Boyd, A.; Rennkamp, B.; Dane, A.J.; Winkler, H. Current approaches to MRV in South Africa: A Scoping Study. Clim. Policy 2014, 14, 397-416. [CrossRef]

19. Mdivani, K.; Hoppe, T. Experience with LEDS and NAMA low carbon strategies: The case of Georgia. Sustainability 2016, 8, 535. [CrossRef]

20. Wenzel, K. Best Practices and Challenges in Supporting MRV in Developing Countries; Deutsche Gesellschaft für Internationale Zusammenarbeit (GIZ) GmbH: Eschborn, Germany, 2016.

21. Neeff, T.; Somogyi, Z.; Schultheis, C.; Mertens, E.; Rock, J.; Brötz, J.; Dunger, K.; Oehmichen, K.; Federici, S. Assessing progress in MRV capacity development: Experience with a scorecard approach. Clim. Policy 2015, 17, 203-212. [CrossRef]

22. Pang, Y.; Thistlethwaite, G.; Watterson, J.; Okamura, S.; Harries, J.; Varma, A.; Le Cornu, E. How To Set Up National MRV Systems; Deutsche Gesellschaft für Internationale Zusammenarbeit (GIZ) GmbH: Eschborn, Germany, 2014.

23. Sharma, S.; Desgain, D.D. Understanding the Concept of Nationally Appropriate Mitigation Action; UNEP Risø Centre: Roskilde, Denmark, 2013.

24. UNFCCC. Toolkit for Non-Annex I Parties on Establishing and Maintaining Institutional Arrangements for Preparing National Communications and Biennial Update Reports; UNFCCC: Bonn, Germany, 2013; ISBN 978-92-9219-123-8.

25. Chandran, R.; Fujita, T.; Fujii, M.; Ashina, S.; Gomi, K.; Boer, R.; Ardiansyah, M.; Maki, S. Expert Networks as Science-Policy Interlocutors in the Implementation of a Monitoring Reporting and Verification (MRV) system. Front. Energy 2018, 12, 376-388. [CrossRef]

26. Garibaldi, J.A.; Winkler, H.; La Rovere, E.L.; Cadena, A.; Palma, R.; Sanhueza, J.E.; Tyler, E.; Torres Gunfaus, M. Comparative Analysis of Five Case Studies: Commonalities and Differences in Approaches to Mitigation Actions in Five Developing Countries. Clim. Dev. 2014, 6, 59-70. [CrossRef]

27. Ministry of Environment and Natural Resources Protection of Georgia. Georgia's Intended Nationally Determined Contribution Submission to the UNFCCC. Available online: https://www4.unfccc.int/sites/ NDCStaging/Pages/Party.aspx?party=GEO (accessed on 24 September 2020).

28. Ministry of Environment and Natural Resources Protection of Georgia. Georgia's Third National Communication to the UNFCCC. Available online: https://unfccc.int/sites/default/files/resource/Geonc3.pdf (accessed on 24 September 2020).

29. NIRAS. Improving Energy Efficiency in Existing Public and Private Buildings. NAMA Concept Note; NIRAS: Copenhagen, Denmark, 2017. 
30. Schauss, V.; De Torre, L.; Pedersen, M. Summary Report of the Second Phase of the Information Matters Project; Bonn \& Eschborn, Germany, 2018. Available online: https:/www.transparency-partnership.net/system/files/ document/Summary \%20report\%20of\%20the \%20second\%20phase \%20of\%20the\%20project.pdf (accessed on 27 November 2020).

31. Energy Community Energy Efficiency Directive. Available online: https://www.energy-community.org/ implementation/Georgia/EE.html (accessed on 21 September 2020).

32. NIRAS. Energy Efficicency Improvements in Public Buildings and the Use of Renewables and Alternative Energy in Georgia. Feasibility Study; NIRAS: Copenhagen, Denmark, 2017.

33. E5P. E5P Grant Agreement Signed for NEFCO's Energy Efficiency Project in Georgia. Available online: https://georgia.e5p.eu/2018/07/04/e5p-grant-agreement-signed-for-nefcos-energy-efficiency-projectin-georgia/ (accessed on 24 September 2020).

34. Ministry of Environmental Protection and Agriculture. Georgia's Second Biennial Update Report. Available online: https://unfccc.int/sites/default/files/resource/2019.06.13_BUR2_2019_Eng.pdf (accessed on 24 September 2020).

35. Kiss, A. Engaging Countries: Strengthening Compliance with Environmental Accords; Edith, B.W., Harold, K.J., Eds.; The MIT Press: Cambridge, MA, USA; London, UK, 1998; p. 589. [CrossRef]

36. O'Neill, K. The Environment and International Relations, 2nd ed.; Cambridge University Press: Cambridge, MA, USA, 2017; ISBN 978-1107671713.

37. Marr, M.A.; Marett, D.A.; Wohlgemuth, N. MRV in Practice-Connecting Bottom-Up and Top-Down Approaches for Developing National MRV Systems for NDCs. Partnership on Transparency in the Paris Agreement:2018. Available online: https://www.transparency-partnership.net/system/files/document/GH_New\%20Climate_ MRV\%20in\%20Practice_2018.pdf (accessed on 27 November 2020).

38. DTU; UNEP; NIRAS. Analysis of the Requirements of Developing Countries, Especially LDCs and SIDS to Implement the ETF of the PA; NIRAS: Copenhagen, Denmark, 2019.

39. Mitchell, R.B. Intentional Oil Pollution at Sea: Environmental Policy and Treaty Compliance; MIT Press: Cambridge, MA, USA, 1994; ISBN 0-262-13303-2.

40. Greiner, S.; Chagas, T.; Krämer, N.; Michaelowa, A.; Brescia, D.; Hoch, S. Moving Towards Next Generation Carbon Markets. Observations From Article 6 Pilots; Climate Focus: Amsterdam, The Netherlands, 2019; Available online: https://www.climatefocus.com/sites/default/files/Moving-toward-next-generation-carbonmarkets_update-june-2019-1.pdf (accessed on 27 November 2020).

41. KliK. KLiK. Available online: https://www.international.klik.ch/en/Home.182.html (accessed on 21 September 2020).

Publisher's Note: MDPI stays neutral with regard to jurisdictional claims in published maps and institutional affiliations.

(C) 2020 by the authors. Licensee MDPI, Basel, Switzerland. This article is an open access article distributed under the terms and conditions of the Creative Commons Attribution (CC BY) license (http://creativecommons.org/licenses/by/4.0/). 